OPEN ACCESS

Edited by:

Tariq Aziz,

University of Agriculture, Pakistan

Reviewed by:

Jeff Wolt,

lowa State University, United States

Federico Vita,

University of Florence, Italy

*Correspondence:

Kevin Smith

kfsmith@unimelb.edu.au

Specialty section:

This article was submitted to

Plant Nutrition,

a section of the journa

Frontiers in Plant Science

Received: 02 July 2020 Accepted: 12 August 2020

Published: 27 August 2020

Citation:

Wang J, Dimech AM, Spangenberg G,

Smith K and Badenhorst P (2020)

Rapid Screening of Nitrogen Use

Efficiency in Perennial Ryegrass

(Lolium perenne L.) Using Automated

Image-Based Phenotyping.

Front. Plant Sci. 11:565361.

doi: 10.3389/fp/s.2020.565361

\section{Rapid Screening of Nitrogen Use Efficiency in Perennial Ryegrass (Lolium perenne L.) Using Automated Image-Based Phenotyping}

\author{
Junping Wang ${ }^{1}$, Adam M. Dimech ${ }^{2}$, German Spangenberg ${ }^{2,3}$, Kevin Smith ${ }^{1,4 *}$ \\ and Pieter Badenhorst ${ }^{1}$ \\ ${ }^{1}$ Agriculture Victoria Research, Hamilton, VIC, Australia, ${ }^{2}$ AgriBio Centre for AgriBioscience, Agriculture Victoria Research, \\ Bundoora, VIC, Australia, ${ }^{3}$ School of Applied Systems Biology, La Trobe University, Bundoora, VIC, Australia, ${ }^{4}$ The Faculty \\ of Veterinary and Agricultural Sciences, The University of Melbourne, Parkville, VIC, Australia
}

Perennial ryegrass (Lolium perenne L.) is a dominant species in temperate Australian pastures. Currently, nitrogenous fertilizers are used to support herbage production for pasture and fodder. Increasing the nitrogen use efficiency (NUE) of pasture grasses could decrease the amount of fertilizer application and reduce nitrogen $(\mathrm{N})$ leaching into the environment. NUE, defined as units of dry matter production per unit of supplied nitrogen, is a complex trait in which genomic selection may provide a promising strategy in breeding. Our objective was to develop a rapid, high-throughput screening method to enable genomic selection for y -60NUE in perennial ryegrass. NUE of 76 genotypes of perennial ryegrass from a breeding population were screened in a greenhouse using an automated imagebased phenomics platform under low $(0.5 \mathrm{mM})$ and moderate $(5 \mathrm{mM}) \mathrm{N}$ levels over 3 consecutive harvests. Significant $(p<0.05)$ genotype, treatment, and genotype by treatment interactions for dry matter yield and NUE were observed. NUE under low and moderate $\mathrm{N}$ treatments was significantly correlated. Of the seven plant architecture features directly extracted from image analysis and four secondarily derived measures, mean projected plant area (MPPA) from the two side view images had the highest correlation with dry matter yield $(r=0.94)$. Automated digital image-based phenotyping enables temporal plant growth responses to $\mathrm{N}$ to be measured efficiently and non-destructively. The method developed in this study would be suitable for screening large populations of perennial ryegrass growth in response to $\mathrm{N}$ for genomic selection purposes.

Keywords: perennial ryegrass, biomass, imaging, nitrogen use efficiency, phenomics

\section{INTRODUCTION}

Global population growth demands a continuing increase in the efficiency of agricultural production. The application of nitrogenous fertilizers to crops and pastures can improve productivity, but also adds to the cost of production whilst contributing to nutrient runoff and the emission of nitrous oxide, a greenhouse gas, through denitrification. Global total nitrogen $(\mathrm{N})$ consumption and average application 
rate on cropland increased more than eight times between 1961 and 2013 (Lu and Tian, 2017). The N nutrition of dairy pasture systems in southern Australia relies almost completely on $\mathrm{N}$ fertilizer today (Rawnsley et al., 2019). Therefore, the challenge remains of how to achieve high production with less cost and lower environmental impact. Several strategies have been identified that could reduce the demand for $\mathrm{N}$ fertilizer in agriculture. For plant breeders, the selection and breeding of plant cultivars that capture $\mathrm{N}$ and convert it to protein more efficiently would offer considerable benefit. Raun and Johnson (1999) demonstrated that a $1 \%$ increase in nitrogen use efficiency (NUE) in cereal production worldwide would result in US \$235 million in savings from reduced annual applications of $\mathrm{N}$ fertilizer in addition to the environmental and social benefits.

NUE is known to be a complex quantitative trait and many genes are involved including for nitrogen signalling, uptake, transport/remobilization, and transcription factors (Han et al., 2015; Liu et al., 2015; Li et al., 2017). For a quantitative trait, genomic selection (GS) provides a promising strategy in breeding (Hayes et al., 2013). However, GS depends on the availability of an accurate and high-throughput phenotyping approach to be successful, which has historically been a challenging bottleneck. New technologies in image-based phenotyping are now allowing researchers to overcome these experimental limitations.

Perennial ryegrass is a dominant species in temperate pastures. $\mathrm{N}$ fertilizer greatly impacts perennial ryegrass growth, development and chemical composition, which is related to herbage quality for grazing livestock. A widely adopted application rate recommendation was 20-60 Urea-N kg ha ${ }^{-1}$ after grazing (Rawnsley et al., 2019). Sometimes the rates are greater in more intensive systems (Gislum et al., 2003; Gourley et al., 2017). Differences in NUE among perennial ryegrass cultivars after defoliation were reported using hydroponics (Wilkins et al., 1997) and field trials under variable N application rates (Wilkins et al., 2000). The variation among cultivars indicated selection and breeding for improving NUE via GS would be possible. However, these researchers were working at the cultivar level and only a limited number were tested whilst the methodologies were not high throughput. Development of GS for improving NUE in perennial ryegrass requires rapid and high-throughput effective screening methods.

Plant phenotyping in controlled environments can be particularly useful in studying different genotypes in response to specific conditions and eliminating variation caused by other factors. For the past decade, there has been increased research into applying image-based high-throughput phenotyping in controlled environments for different crops and traits (Das Choudhury et al., 2019). Recently, an automated image-based system was used to screen NUE for wheat varieties at the vegetative phase (Nguyen et al., 2019). To date, there have been limited reports of using such systems for forage grasses, where unique challenges exist due to differences in plant architecture such as dense tillers, occlusion of leaves, and regrowth after repetitive defoliation. Traditionally, pasture grass response to $\mathrm{N}$ supply is measured as a biomass yield by destructively harvesting the foliage. Non-destructive measurements such as tiller count and leaf area estimates have also been applied for perennial ryegrass. However, these measurements still involve manual handling of plants and may cause inadvertent damage. Automated digital image-based analysis offers a nondestructive, high throughput, and less invasive option.

The objectives of this study were to develop an image-based method for rapid NUE screening for perennial ryegrass and to explore the genetic variation of NUE within an advanced breeding population under low and moderate $\mathrm{N}$ levels.

\section{MATERIALS AND METHODS}

\section{Plant Materials}

Seventy-six perennial ryegrass genotypes from an advanced breeding population were used in this study. Plants were initially grown in a greenhouse in plastic pots $(120 \mathrm{~mm}$ diameter $)$ with commercial potting mix (BioGrow Australia Pty. Ltd., Mount Gambier, South Australia, Australia) at Agriculture Victoria, Hamilton Centre, Hamilton, Victoria, Australia. Each plant was propagated into 8 clonal ramets of 5 tillers each into forestry tubes $(50 \times 50 \times 120 \mathrm{~mm})$ three weeks before setting up the experiment. Plants were grown in the same greenhouse with temperature set to $22^{\circ} \mathrm{C}$ under ambient light conditions.

\section{Imaging Greenhouse and Experiment Design}

The phenotyping experiment was conducted at Plant Phenomics Victoria, Bundoora, Victoria, Australia, which is equipped with two greenhouses containing a LemnaTec 3D Scanalyzer phenomics platform (LemnaTec, GmbH, Aachen, Germany; Figure 1).

A randomized complete block design was used with two $\mathrm{N}$ levels and four replicates. A total of 608 pots were laid out into 16 rows with 38 pots per row. Each replicate consisted of four rows, i.e. two rows for each of the low $\mathrm{N}$ and moderate $\mathrm{N}$ treatments. The 76 genotypes were randomly allocated within each of the treatment rows. Two levels of $\mathrm{N}$ treatments were alternated between the rows.

\section{Treatment and Growth Conditions}

Plants were cut to $5 \mathrm{~cm}$ height at the commencement of the experiment and transplanted into white $200 \mathrm{~mm}$ diameter pots (catalogue P200E04, Garden City Planters Pty. Ltd., Dandenong South, Victoria, Australia). Pots were filled with potting mix containing coir peat, composted pine bark, composted sawdust, SaturAid ${ }^{\circledR}$ (soil-wetting agent), lime, and gypsum (Australian Growing Solutions Pty. Ltd., Tyabb, Victoria, Australia). No nutrient components were added to the potting mix. Pots were placed into carriers which were tagged with radio frequency identification (RFID) chips for tracking and moved in the greenhouse on the LemnaTec Scanalyzer 3D via a series of conveyors to watering and imaging stations. Watering was controlled programmatically and checked daily via weighing scales, which allowed estimates of evapotranspiration to be calculated for each individual pot (Ge et al., 2016). Plants were grown in the greenhouse at $22^{\circ} \mathrm{C}$ for $16 \mathrm{~h}$ (day) and $15^{\circ} \mathrm{C}$ for $8 \mathrm{~h}$ (night). Natural sunlight was supplemented with full-spectrum light-emitting diode (LED) growth lights (Samsung, Seoul, South 


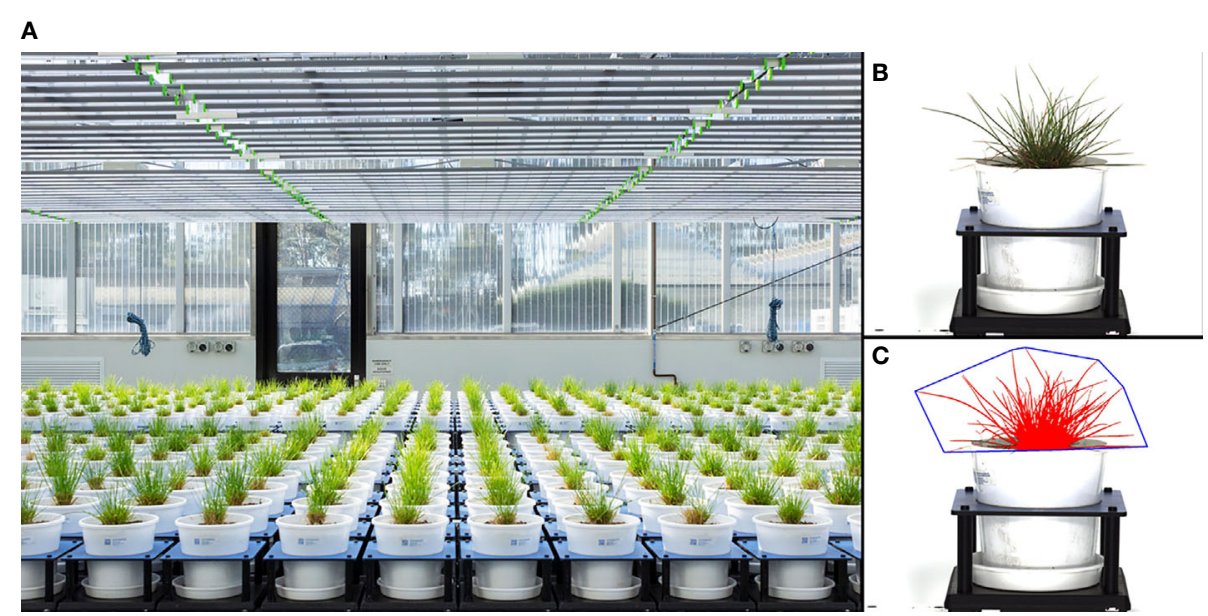

FIGURE 1 | Imaging greenhouse (A), a raw side-view image of a perennial ryegrass plant (B), and the processed image object from the raw image (C). The diameter of the pots is $200 \mathrm{~mm}$.

Korea) with an approximate photosynthetic photon flux of 600 $\mu \mathrm{mol} \mathrm{m} \mathrm{s}^{-2}$ at canopy height when it fell below $500 \mu \mathrm{mol} \mathrm{m} \mathrm{s}^{-2}$.

Half-strength Hoagland solution (Hoagland and Arnon, 1950) $(100 \mathrm{ml}$ ) with modified $\mathrm{N}$ levels of $0.5 \mathrm{mM}$ or $5 \mathrm{mM}$ (Jiang et al., 2016) was applied to each pot twice weekly. $\mathrm{KNO}_{3}$ and $\mathrm{Ca}\left(\mathrm{NO}_{3}\right)_{2}$ were used as nitrate sources in the solution. Potassium and calcium levels were equalized across treatments by adding $\mathrm{KCl}$ and $\mathrm{CaCl}_{2}$ into the lesser $\mathrm{N}$ treatment solution (Jiang et al., 2016).

\section{Image Acquisition and Analysis}

Imaging was conducted twice a week via a series of visiblespectrum (red-green-blue, RGB) cameras (Prosilica GT, Allied Vision Technologies GmbH, Stadtroda, Germany) fitted with a $50 \mathrm{~mm}$ focal lens ( $\mathrm{T}^{\star} 250 \mathrm{ZF}$, Carl Zeiss AG, Oberkochen, Germany) and located within an imaging cabinet. RGB images of each plant were taken from above (top view) and from the side at two angles $\left(0^{\circ}\right.$ and $\left.90^{\circ}\right)$. Plant images were analyzed using a customized grid programmed within LemnaGrid software before the plant architecture features (Table 1) were extracted. The imagery data were treated as repeated measures.

The following derived volume estimations, which have been reported correlated to biomass in maize (Klukas et al., 2014), field pea (Nguyen et al., 2018) and wheat (Nguyen et al., 2019) were calculated.

$$
\begin{gathered}
V=A_{s .0^{\circ}}+A_{s .90^{\circ}}+A_{t} \\
V_{\text {lemnatec }}=\sqrt{A_{s .0^{\circ}} \times A_{s .90^{\circ}} \times A_{t}} \\
\mathrm{~V}_{\text {keygene }}=A_{s .0^{\circ}}+A_{s .90^{\circ}}+\log \left(\frac{\mathrm{A}_{\mathrm{t}}}{3}\right)
\end{gathered}
$$

Where $A_{s .0^{\circ}}$ is the projected area from the $0^{\circ}$ side view image, $A_{s .90^{\circ}}$ is the projected area from the $90^{\circ}$ side view image, and $A_{t}$ is

\begin{tabular}{|c|c|c|}
\hline Trait & Unit & Description \\
\hline Area & pixel & Projected plant area from top or side view images \\
\hline Calliper Length & pixel & The longest dimension of the projected canopy \\
\hline Compactness & & A ratio of projected plant area to convex hull area \\
\hline Convex Hull Area & pixel & Projected minimum area contained the object \\
\hline Convex Hull & pixel & Circumference of the projected convex hull \\
\hline \multicolumn{3}{|l|}{ Circumference } \\
\hline Width & pixel & Projected maximum length horizontally \\
\hline Height & pixel & Projected maximum length vertically \\
\hline
\end{tabular}
the projected area from the top view image.
TABLE 1 | Features extracted from digital RGB images of perennial ryegrass plants.

\section{Destructive Harvests and Nitrogen Use Efficiency}

The total duration of the experiment was 3 months. Three manual cuts of individual plants were conducted at approximately 4 -week intervals and at $5 \mathrm{~cm}$ height from the potting mix. Chronologically, the corresponding three regrowth periods were defined as acclimation phase (AP), experimental phase-1 (EP-1), and experimental phase-2 (EP-2). The fresh biomass (FM) of plant material was measured and samples were then dried at $60^{\circ} \mathrm{C}$ for $48 \mathrm{~h}$ and dry biomass (DM) was weighed. The AP allowed plants to establish after transplanting and acclimate to the experimental conditions, whilst also permitting the consumption of any residual $\mathrm{N}$ from the root surface and metabolization of excess $\mathrm{N}$ stored in the roots and crown to be completed so that a proper assessment of the $\mathrm{N}$ treatments in EP-1 and EP-2 could be made.

NUE was calculated in both EP-1 and EP-2 as follows:

$$
N U E=\frac{D M(g)}{N_{S}(g)}
$$

where DM is the dry biomass, and $\mathrm{N}_{\mathrm{s}}$ is the supplied $\mathrm{N}$.

Seven applications of the nutrient solution were applied to each pot during each of the experimental phases, which is 
equivalent to $4.9 \mathrm{mg} \mathrm{N}$ per pot in the low $\mathrm{N}$ treatment and $49 \mathrm{mg}$ $\mathrm{N}$ in the moderate $\mathrm{N}$ treatment. The application rate of $49 \mathrm{mg} \mathrm{N}$ per pot is equivalent to approximately $20 \mathrm{~kg} / \mathrm{ha}$.

\section{Plant Growth Analysis}

Absolute plant growth rate (AGR) on DM ( $\left.\mathrm{g} \mathrm{d}^{-1}\right)$ in EP-1 and EP-2 were calculated as average accumulated DM per day during their respective growth periods. AGR on mean projected plant area (MPPA, pixel $\mathrm{d}^{-1}$ ) from the two side view images was calculated as follows:

$$
A G R=\frac{M P P A_{2}-M P P A_{1}}{t_{2}-t_{1}}
$$

and relative growth rate (RGR) on MPPA was calculated as follows:

$$
R G R=\frac{\operatorname{Ln}\left(M P P A_{2}\right)-\operatorname{Ln}\left(M P P A_{1}\right)}{t_{2}-t_{1}}
$$

where $t_{2}$ and $t_{1}$ were the respective finish and start time points of a growth period, $\operatorname{Ln}\left(\mathrm{MPPA}_{2}\right)$ and $\operatorname{Ln}\left(\mathrm{MPPA}_{1}\right)$ was the natural logarithm of MPPA at the time of $t_{2}$ and $t_{1}$ respectively. The RGR results were given as per day (i.e. $0.2 \mathrm{~d}^{-1}$ is equivalent to $20 \%$ increase in a day) (Poiré et al., 2014).

\section{Statistical Analysis}

Statistical analysis was conducted using GenStat v.18 (VSN International, 2015). Linear mixed model analysis was conducted using a restricted maximum likelihood (REML) approach in GenStat where $\mathrm{N}$ treatment level, genotype and their interaction were fitted as fixed factors and replicate as random factor. The best linear unbiased estimations (BLUEs) of DM and NUE for each genotype under low and moderate $\mathrm{N}$ levels were obtained from REML and plotted in Microsoft Excel. Pearson's correlation coefficient $(r)$ between features extracted from images and FM and DM were computed and plotted using the "PerformanceAnalytics" package in R statistical software (version R-3.5.1) (R Core Team, 2017).

\section{RESULTS}

\section{Perennial Ryegrass Genotype Response to Different N Supplies}

REML analysis showed that DM was significantly greater in plants with moderate $\mathrm{N}$ compared to those with low $\mathrm{N}$ supply $(\mathrm{p}<0.001)$ in both EP-1 and EP-2 (Figure 2A). Different genotypes within each treatment also showed a significant difference in DM $(\mathrm{p}<0.001)$ and the genotype by $\mathrm{N}$ treatment interaction was also significant $(\mathrm{p}<0.001)$. In contrast, NUE was signicantly less in moderate $\mathrm{N}$ supply than that in low $\mathrm{N}$ supply $(\mathrm{p}<0.001)$ in both EP-1 and EP-2 (Figure 2B). Genotype effect was significant for NUE ( $p<0.001)$ in both EP-1 and EP-2 and genotype by $\mathrm{N}$ interaction was also significant in EP-1 $(\mathrm{p}<0.001)$ and in EP-2 ( $\mathrm{p}<0.05)$.

There was significant variation among genotypes for DM and NUE under both low and moderate $\mathrm{N}$ supplies (Table 2). The estimates of NUE under low N supply were in a range of 61.7-476.5 and 72.4-353.1 $\mathrm{g} \mathrm{DM} \mathrm{g}^{-1} \mathrm{Ns}$ in EP-1 and EP-2, respectively. The population mean were significantly lower in EP-2. The estimates of NUE under moderate $\mathrm{N}$ supply were in a range of 6.0-77.4 and 11.8-83.0 $\mathrm{g} \mathrm{DM} \mathrm{g}^{-1} \mathrm{Ns}$ in EP-1 and EP-2, respectively. There was no difference of population means between EP-1 and EP-2. In terms of NUE, the best genotype was over 4 times and 7 times greater than that of the worst geotype under low and moderate $\mathrm{N}$ supply, respectively. The NUE variance in EP-1 was two-fold of that in EP-2 under low $\mathrm{N}$ whilst the variance was no different between EP-1 and EP-2 under moderate N. The correlations of DM and NUE between low and moderate $\mathrm{N}$ treatments were significant in both EP-1 and EP-2 (Figure 3).
A

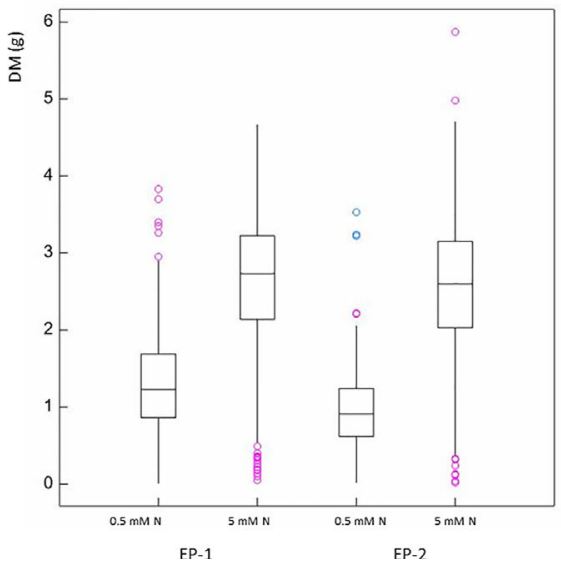

B

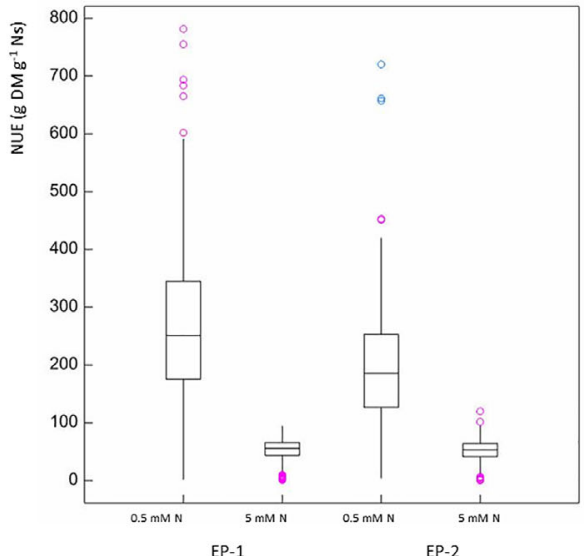

FIGURE 2 | Box and whisker plots of dry biomass (A) and nitrogen use efficiency (B) in experimental phase-1 (EP-1) and experimental phase-2 (EP-2) under two levels of $\mathrm{N}$ treatment $(0.5 \mathrm{mM}$ and $5 \mathrm{mM} \mathrm{N})$. 
TABLE 2 | Summary statistics of best linear unbiased estimations of dry biomass (DM) and nitrogen use efficiency (NUE) of 76 genotypes of a perennial ryegrass breeding population under two levels of $\mathrm{N}$ in two experimental phases (EP-1 and EP-2).

\begin{tabular}{|c|c|c|c|c|c|c|c|}
\hline & N Level & \multicolumn{3}{|c|}{ DM (g) } & \multicolumn{3}{|c|}{ NUE (g DM g g $\left.{ }^{-1} \mathrm{Ns}\right)$} \\
\hline EP-1 & $0.5 \mathrm{mM}$ & $1.29 \pm 0.446$ & $0.30-2.34$ & 0.35 & $263.3 \pm 91.18$ & $61.7-476.5$ & 0.35 \\
\hline \multirow[t]{2}{*}{ EP-2 } & $0.5 \mathrm{mM}$ & $0.95 \pm 0.295$ & $0.36-1.73$ & 0.31 & $194.5 \pm 60.22$ & $72.4-353.1$ & 0.31 \\
\hline & $5 \mathrm{mM}$ & $2.57 \pm 0.720$ & $0.58-4.07$ & 0.28 & $52.31 \pm 14.74$ & 11.8-83.0 & 0.28 \\
\hline
\end{tabular}

S.D., standard deviation; CV, coefficient variation.

\section{Relationships Between Features Extracted From Images and Biomass of Perennial Ryegrass Plants}

The correlations between FM, DM, and the 7 plant architecture features (Table 1) from side view and top view images are shown in Figures 4A, B, respectively. All traits were significantly correlated with varied correlation coefficients. Out of the 7 features, the projected plant area of the side view image demonstrated the highest correlation with FM and DM. The mean projected plant area (MPPA) from the two side view images slightly improved the correlation with FM and DM than a single image alone (Figure 5). The derived $V, V_{\text {LemnaTec }}$ and $V_{\text {keygene }}$ were also highly correlated with FM and DM with correlation coefficient of $0.947,0.946,0.954$ and $0.933,0.928$ and 0.940 , respectively. $V_{\text {keygene }}$ was as good as the MPPA. The plant architecture features showed slightly higher correlations with FM than with DM.

\section{Temporal Dynamics of MPPA}

Since the MPPA from the two side view images showed the highest correlation with FM and DM, the temporal dynamics of MPPA after defoliation were investigated under two $\mathrm{N}$ treatments for AP, EP-1 and EP-2 (Figure 6). In AP, MPPA accumulation showed a linear trend over time and there was no significant difference between the two nitrogen treatment levels. In EP-1 and EP-2, MPPA accumulation under the $5 \mathrm{mM} \mathrm{N}$ treatment was significantly faster than those under $0.5 \mathrm{mM} \mathrm{N}$ treatment. Under the low $\mathrm{N}$ treatment, MPPA continued to increase within 4 weeks of defoliation, however, the accumulation of MPPA became much slower after 3 weeks and the limited $\mathrm{N}$ restricted plant growth. The absolute growth rate (AGR) on MPPA increased in the first week after defoliation and then decreased thereafter under both low and moderate N (Figure 7). The relative growth rate (RGR) declined sharply within the 3 weeks after defoliation then decreased gradually thereafter.

The AGR on the DM basis was 0.046 and $0.092 \mathrm{~g} \mathrm{~d}^{-1}$ under 0.5 and $5 \mathrm{mM} \mathrm{N}$ in the EP- 1 and 0.035 and $0.094 \mathrm{~g} \mathrm{~d}^{-1}$ in the EP-2. AGR on the MPPA basis was 2555 and 4858 pixel $\mathrm{d}^{-1}$ under 0.5 and $5 \mathrm{mM} \mathrm{N}$ in EP-1 and 2310 and 5168 pixel $\mathrm{d}^{-1}$ in EP-2. Strong correlations between AGR on DM and MPPA were observed in EP-1 and EP-2 (Figure 8).

\section{DISCUSSION}

\section{Automated Image-Based Phenotyping in Controlled Environments}

In this paper we describe the development of an automated image-based phenotyping methodology to screen NUE in a breeding population of perennial ryegrass.

Our results demonstrated that a LemnaTec Scanalyzer 3D image-based greenhouse phenomics platform can be used to
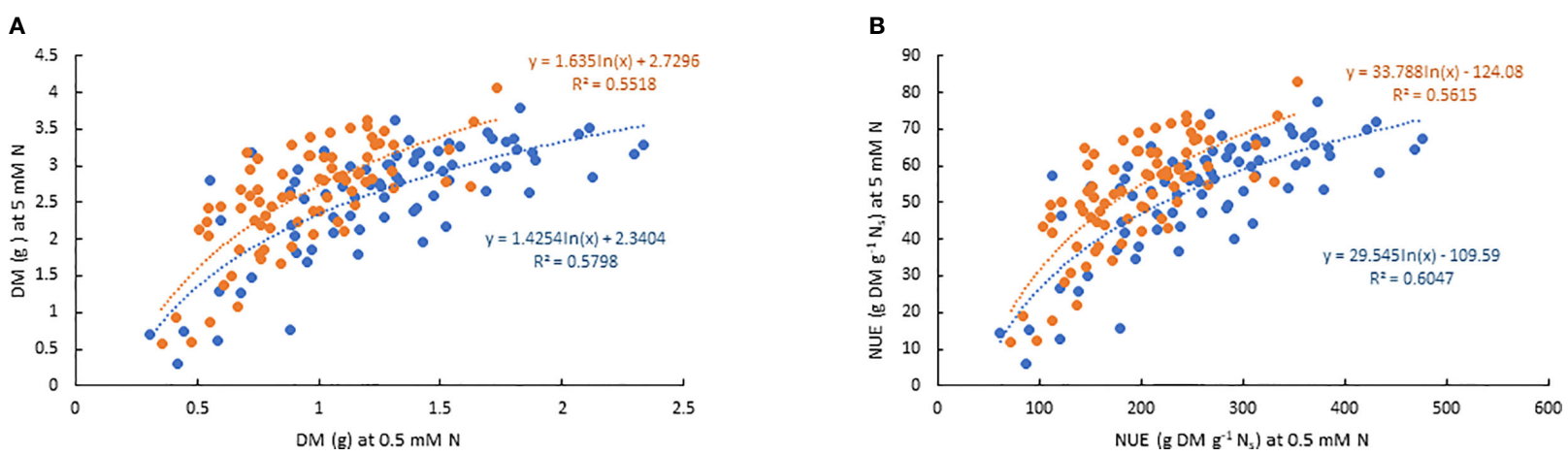

FIGURE 3 | Scatter plots of best linear unbiased estimates (BLUEs) of dry biomass (A) and nitrogen use efficiency (B) of 76 genotypes under two levels of $N$ treatment over the two experimental phases (Blue dots: EP-1; orange dots: EP-2). BLUEs were derived from the restricted maximum likelihood (REML) in GenStat where genotype, $\mathrm{N}$ treatment and their interaction were fitted as fixed factors and replicate was fitted as random factor for each variate in each experimental phase. 


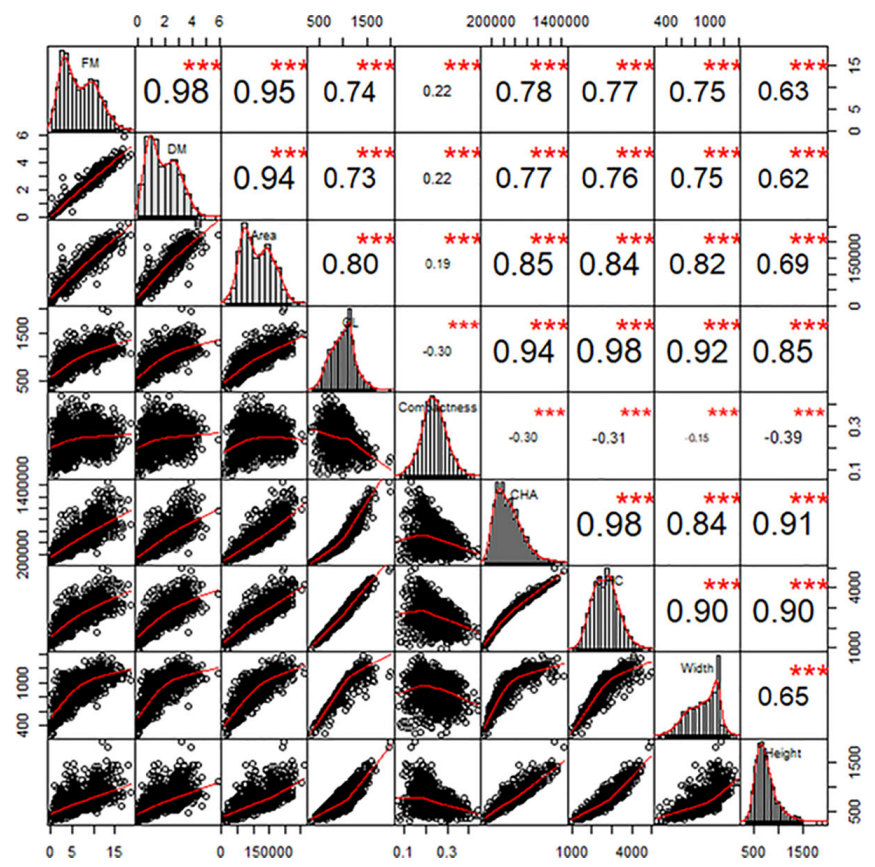

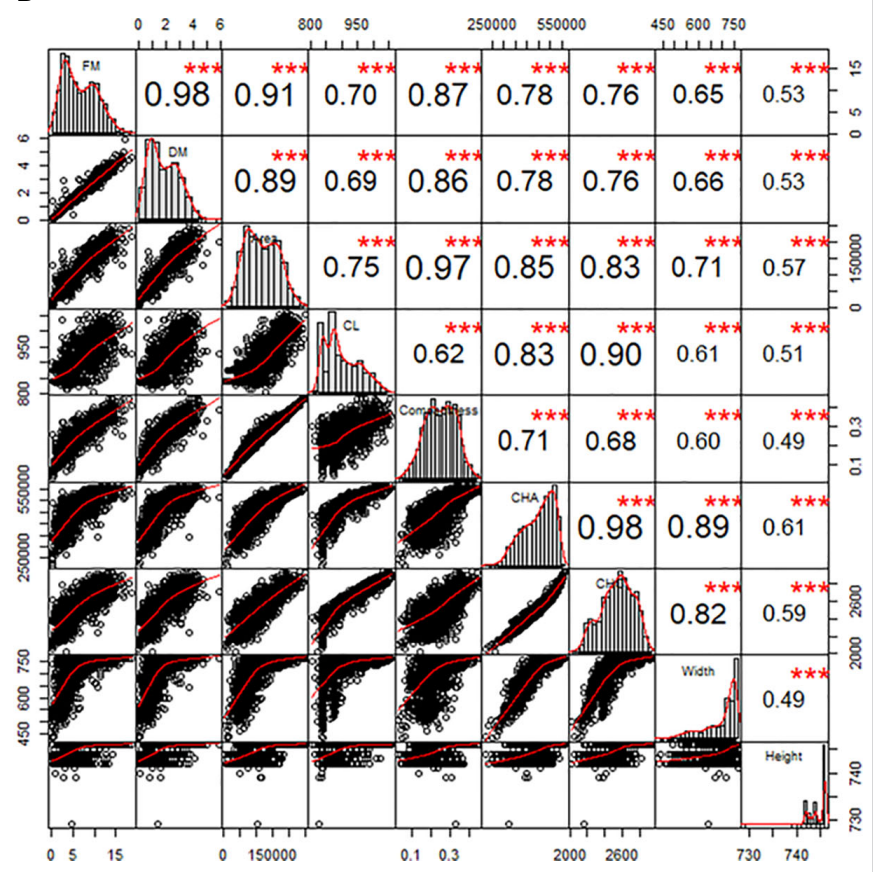

FIGURE 4 | The correlations between features from $0^{\circ}$-side view (A) and top view (B) images and fresh and dry biomass over the two experimental phases. FM, fresh biomass; DM, dry biomass; CL, calliper length; CHA, convex hull area; $\mathrm{CHC}$, convex hull circumference. In each panel, the diagonals are the histograms of individual traits. The windows above and below the diagonals are Pearson's correlation coefficients $(r)$ and bivariate scatter plots with non-parametric regression smooth lines, respectively. The asterisks are the statistically significant levels $\left.{ }^{\star \star *} p<0.001\right)$. Sample number $=1164$
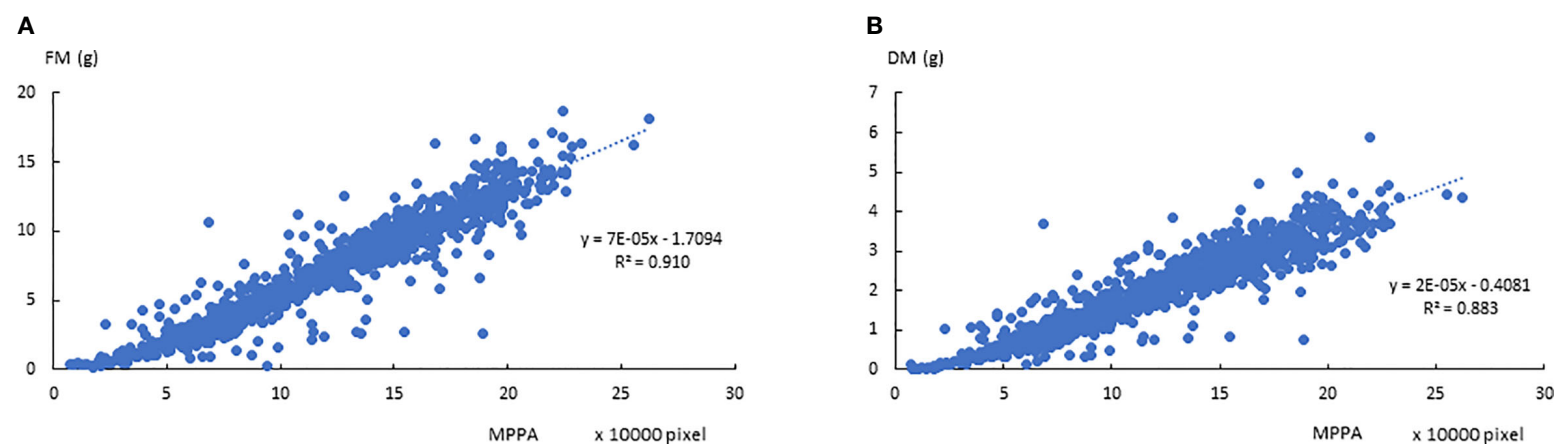

FIGURE 5 | Relationships between the mean projected plant area (MPPA) from $0^{\circ}$ and $90^{\circ}$-side view images and fresh biomass (FM, A) and dry biomass (DM, B) over the two experimental phases.

extract trait features from images as a reliable proxy for numerous traits of interest in perennial ryegrass, including NUE. The aim of this experiment was to quantify seven plant architecture features and four derived measurements, which has been amply demonstrated. In our study, the MPPA and $V_{\text {keygene }}$ showed the highest correlations with FM $(r=0.95)$ and DM $(r=$ 0.94). We also observed a strong correlation between digital volume and FM, as has been shown by others in Brachypodium (Poiré et al., 2014), sorghum (Neilson et al., 2015), field pea early stage of growth (Nguyen et al., 2018), and wheat vegetative phase (Nguyen et al., 2019). In perennial ryegrass, incorporating the digital area from the top view image did not improve the correlation with biomass yield via our MPPA metric. This may be because the perennial ryegrass canopy structure appears denser and more symmetrical when compared to wheat or sorghum. The correlation between MPPA and FM was found to be slightly greater than that between MPPA and DM. Greater correlation between image based data with FM than with DM 
AP

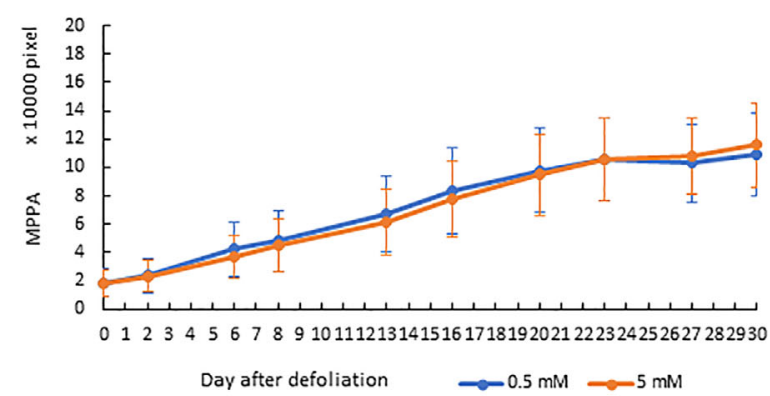

EP-1

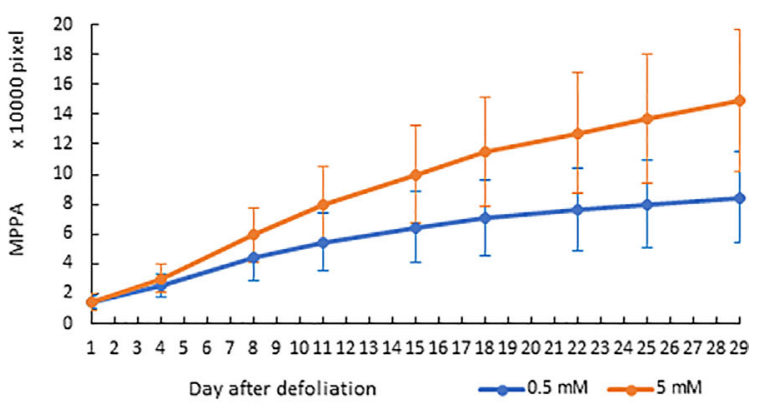

EP-2

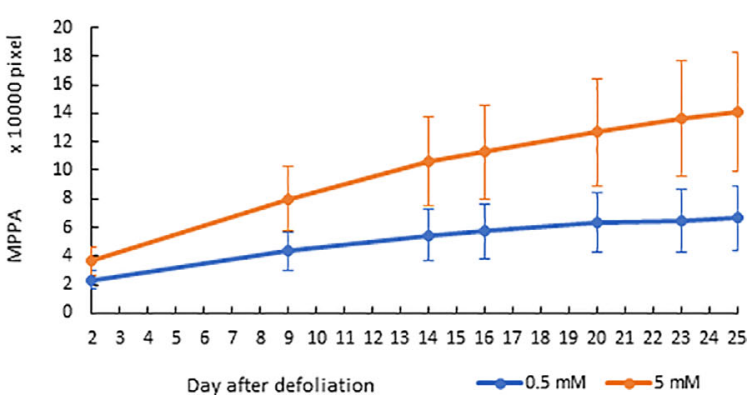

FIGURE 6 | Accumulation of mean projected plant area (MPPA) from $0^{\circ}$ and $90^{\circ}$-side view images in acclimation phase (AP) and experimental phase-1 (EP-1) and phase-2 (EP-2) after defoliation. The error bar is the standard deviation of the mean for the group.

EP-1

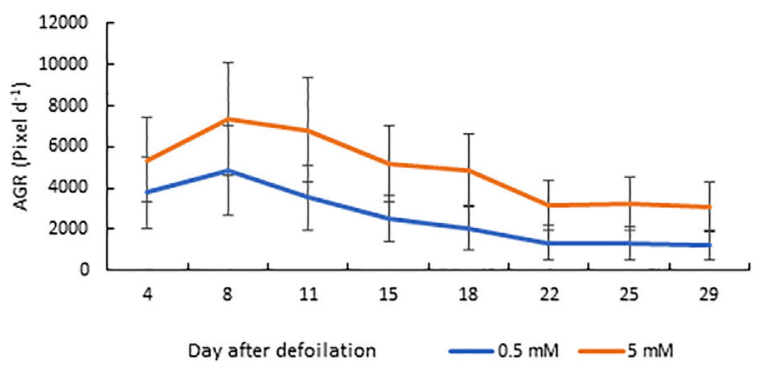

EP-1

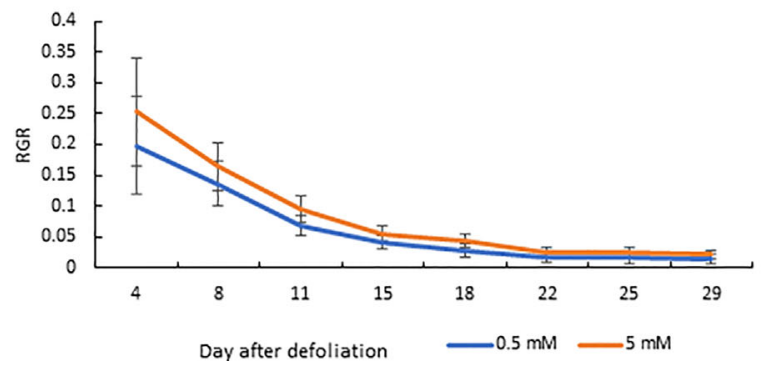

EP-2

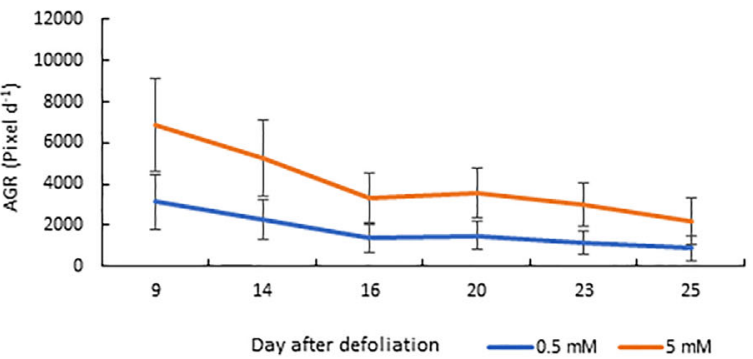

EP-2

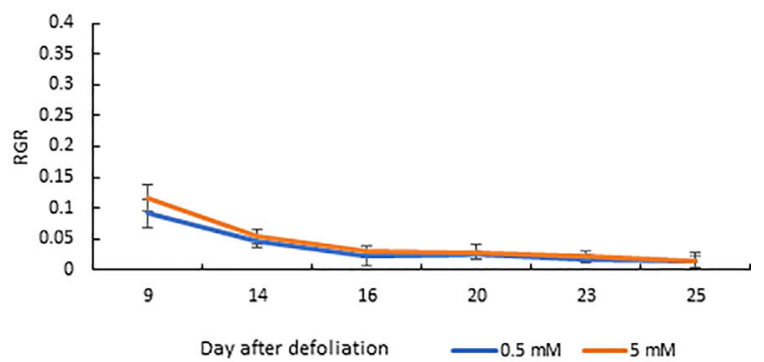

FIGURE 7 | Absolute and relative growth rate (AGR and RGR) over time on the mean projected plant area (MPPA) from the two side view images under two levels of $\mathrm{N}$ treatment $(0.5$ and $5 \mathrm{mM})$ during experimental phase-1 (EP-1) and experimental phase-2 (EP-2). 
EP-1

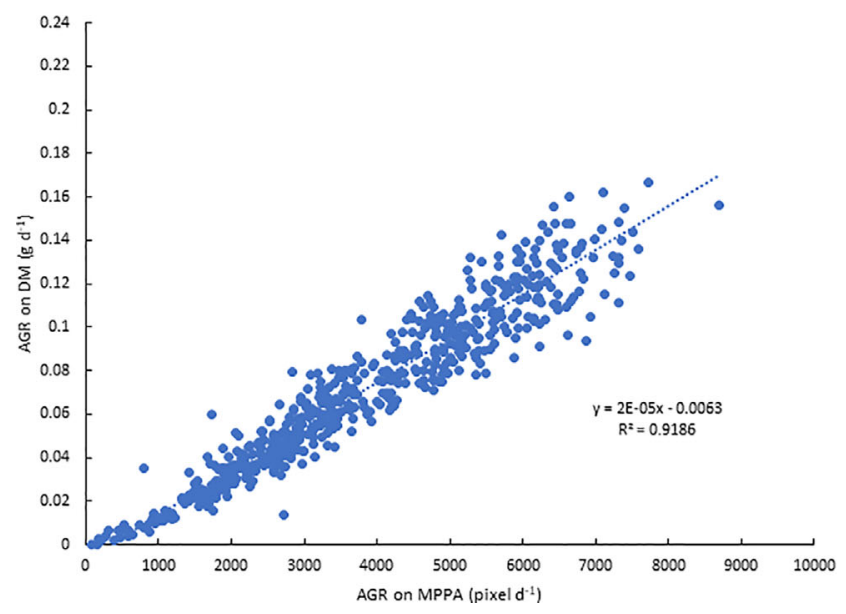

EP-2

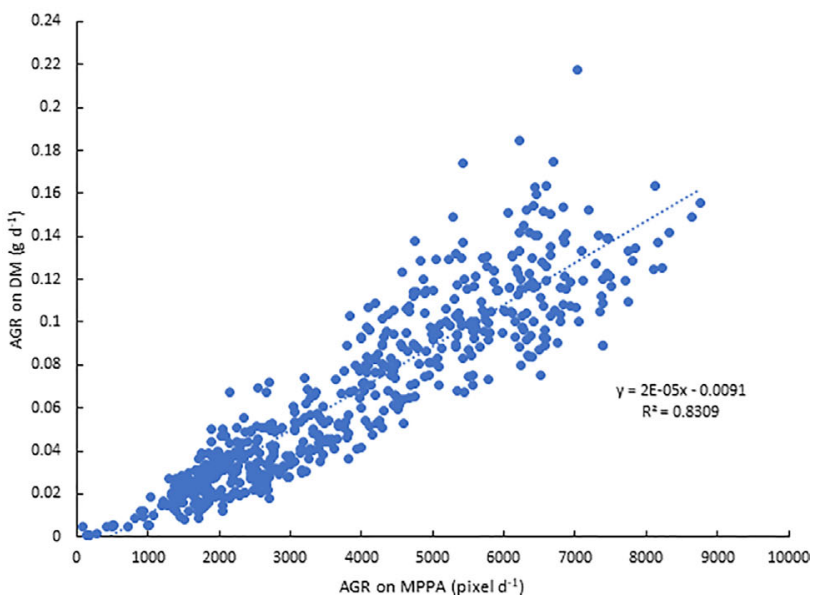

FIGURE 8 | Relationships between absolute growth rate (AGR) on the mean projected plant area (MPPA) from the two side view images and on dry biomass (DM) during experimental phase-1 (EP-1) and experimental phase-2 (EP-2).

was also found in maize (Klukas et al., 2014). This may be because the image features were based on living plants and variation in moisture content in plants were not captured in the RGB imagery. The correlation with DM may be further improved by hyperspectral images by which water content can be estimated (Ge et al., 2016). Furthermore, the features extracted were based on $2 \mathrm{D}$ images; $3 \mathrm{D}$ reconstruction of plant may provide a more accurate estimation (Gibbs et al., 2017).

Our results have demonstrated that we can use image-based phenomics to quantify biomass accumulation and growth in greenhouse-grown perennial ryegrass without the need for destructive harvesting. The savings that this brings are considerable; less labor is required to undertake research of this nature and results can be obtained faster, effectively speeding-up breeding programs.

Breeding for improved NUE through GS may reduce the amount of $\mathrm{N}$ fertilizer application required in the field, with the environmental benefits that this would bring. Our approach provides a useful tool for plant breeders and researchers. Given the complexity of NUE, screening in controlled environments can eliminate other confounding factors which would be impossible to control in field trials, for example water, temperature, and other mineral nutrients in the soil. Whilst field performance would always be the best method for evaluating lines prior to commercial release, our approach permits the screening of large numbers of candidate lines and selecting those which show most promise before field trials need to commence.

In perennial pasture, some of the nutrients stored in underground organs will mobilize to the leaves following grazing and regrowth. So, to screen perennial pasture plant responses to $\mathrm{N}$ supply and NUE, an acclimation period is necessary. One growth cycle of 4 weeks proved to be a suitable time for acclimation in which plant growth response showed no difference between the $\mathrm{N}$ treatment levels (Figure 6). Results from the two experimental phases were consistent (Figures 6 and 7) which indicated good repeatability under these experimental conditions.

\section{NUE of Perennial Ryegrass}

Perennial ryegrass response to $\mathrm{N}$ supply has long been of interest to pasture agronomists. Early work showed the response of tiller number, leaf number and leaf area, dry biomass increased along with the increase of $\mathrm{N}$ application in field plots (O'Brien, 1960) and sand pot culture (Luxmoore and Millington, 1971). It is as expected that greater biomass production was observed under the moderate $\mathrm{N}$ than that under low $\mathrm{N}$ (Table 2). However, higher $\mathrm{N}$ application reduces NUE which is in agreement with previous reports (Jiang et al., 2016). It was found that high plant tissue $\mathrm{N}$ content was correlated with low NUE (Garcez and Monteiro, 2016). This may be the primary reason why NUE under moderate $\mathrm{N}$ were less than that under low $\mathrm{N}$. Nevertheless, significant variations identified within the breeding population in the present study would be a resource for genomic selection. Since the $\mathrm{N}$ concentration of herbage samples were not analyzed in the present study, the differences in NUE attribute to uptake or utilization was unknown.

\section{Plant Growth}

The automated phenotyping greenhouse allows images to be taken within a time series and enables investigation of plant growth response throughout the growth period without sacrificing replicates for destructive harvest (Poire et al., 2014). It is very useful for outcrossing perennial pastoral grasses under repetitive defoliation. The AGR on MPPA under moderate N supply were almost double that under low $\mathrm{N}$ supply. This agrees with the AGR on biomass production under those two $\mathrm{N}$ levels. It was reported that greater biomass production under greater $\mathrm{N}$ was mainly from increased tiller number and tiller size (weight). The temporal RGR 
pattern largely resembled the pattern in Brachypodium which showed an initial decay phase in the first 3 weeks then became more stable, representing the transition from an early exponential growth stage to a late more linear growth stage (Poiré et al., 2014).

In summary, the NUE and plant growth response to $\mathrm{N}$ application were assessed rapidly in a perennial ryegrass breeding population under controlled greenhouse conditions. It provides a tool to screen large populations for genomic selection. The image-based system will be applicable for screening NUE for perennial ryegrass and other comparable forage grasses.

\section{DATA AVAILABILITY STATEMENT}

The raw data supporting the conclusions of this article will be made available by the authors, without undue reservation.

\section{REFERENCES}

Das Choudhury, S., Samal, A., and Awada, T. (2019). Leveraging image analysis for high-throughput plant phenotyping. Front. Plant Sci. 10, 508. doi: 10.3389/ fpls.2019.00508

Garcez, T. B., and Monteiro, F. A. (2016). Nitrogen use of Panicum and Brachiaria cultivars vary with nitrogen supply: II nitrogen use efficiency rankings and partition. Aust. J. Crop Sci. 10, 622-631. doi: 10.21475/ajcs.2016.10.05.p6853B

Ge, Y., Bai, G., Stoerger, V., and Schnable, J. C. (2016). Temporal dynamics of maize plant growth, water use, and leaf water content using automated high throughput rgb and hyperspectral imaging. Comput. Electron Agric. 127, 625632. doi: 10.1016/j.compag.2016.07.028

Gibbs, J. A., Pound, M., French, A. P., Wells, D. M., Murchie, E., and Pridmore, T. (2017). Approaches to three-dimensional reconstruction of plant shoot topology and geometry. Funct. Plant Biol. 44, 62-75. doi: 10.1071/FP16167

Gislum, R., Wollenweber, B., Boelt, B., and Jensen, E. (2003). Uptake and distribution of nitrogen in perennial ryegrass: Effect of additional applications at vegetative growth. J. Plant Nutr. Soil Sci. 26, 2375-2389. doi: 10.1081/PLN-120025466

Gourley, C. J. P., Hannah, M. C., and Chia, K. T. H. (2017). Predicting pasture yield response to nitrogenous fertiliser in australia using a meta-analysisderived model, with field validation. Soil Res. 55, 567. doi: 10.1071/SR17032

Han, M., Okamoto, M., Beatty, P., J Rothstein, S., and Good, A. (2015). The genetics of nitrogen use efficiency in crop plants. Annu. Rev. Genet. 49, 1-15. doi: 10.1146/annurev-genet-112414-055037

Hayes, B. J., Cogan, N. O.II, Pembleton, L. W., Goddard, M. E., Wang, J., Spangenberg, G. C., et al. (2013). Prospects for genomic selection in forage plant species. Plant Breed. 132, 133-143. doi: 10.1111/pbr.12037

Hoagland, D. R., and Arnon, D. I. (1950). The water-culture method for growing plants without soil. California Agr. Expt. Sta Circ. 347, 1-32.

Jiang, Y., Li, Y., Nie, G., and Liu, H. (2016). Leaf and root growth, carbon and nitrogen contents, and gene expression of perennial ryegrass to different nitrogen supplies. J. Am. Soc. Hort. Sci. 141, 555-562. doi: 10.21273/JASHS03883-16

Klukas, C., Chen, D., and Pape, J. M. (2014). Integrated analysis platform: An open-source information system for high-throughput plant phenotyping. Plant Physiol. 165, 506-518. doi: 10.1104/pp.113.233932

Li, H., Hu, B., and Chu, C. (2017). Nitrogen use efficiency in crops: Lessons from arabidopsis and rice. J. Exp. Bot. 68, 2477-2488. doi: 10.1093/jxb/erx101

Liu, Q., Chen, X., Wu, K., and Fu, X. (2015). Nitrogen signaling and use efficiency in plants: What's new? Curr. Opin. Plant Biol. 27, 192-198. doi: 10.1016/ j.pbi.2015.08.002

Lu, C., and Tian, H. (2017). Global nitrogen and phosphorus fertilizer use for agriculture production in the past half century: Shifted hot spots and nutrient imbalance. Earth Syst. Sci. Data 9, 181-192. doi: 10.5194/essd-9-181-2017

Luxmoore, R. J., and Millington, R. J. (1971). Growth of perennial ryegrass (Lolium perenne L.) in relation to water, nitrogen, and light intensity. Plant Soil. 34, 269-281. doi: $10.1007 / \mathrm{bf} 01372784$

\section{AUTHOR CONTRIBUTIONS}

$\mathrm{JW}, \mathrm{PB}$, and $\mathrm{KS}$ designed the experiment. JW and $\mathrm{AD}$ conducted the experiment. JW analyzed the data and drafted the manuscript. AD, $\mathrm{PB}, \mathrm{KS}, \mathrm{JW}$, and GS reviewed and edited the manuscript. GS final approved the submitted version.

\section{ACKNOWLEDGMENTS}

The authors acknowledge technical assistance provided by Katrina Hill, Carly Elliott, Jess Frankel, Michela Murry, Darren Keane, Russel Elton, Darren Picket, Jim Wilson, Michelle Drayton, Maiko Shinozuka, and Preeti Thakur.

Financial support for this work was received from Agriculture Victoria and Dairy Australia through the DairyBio initiative.

Neilson, E. H., Edwards, A. M., Blomstedt, C. K., Gleadow, R. M., Møller, B. L., and Berger, B. (2015). Utilization of a high-throughput shoot imaging system to examine the dynamic phenotypic responses of a c4 cereal crop plant to nitrogen and water deficiency over time. J. Exp. Bot. 66, 1817-1832. doi: 10.1093/jxb/eru526

Nguyen, G. N., Norton, S. L., Rosewarne, G. M., James, L. E., and Slater, A. T. (2018). Automated phenotyping for early vigour of field pea seedlings in controlled environment by colour imaging technology. PloS One 13, e0207788. doi: 10.1371/journal.pone.0207788

Nguyen, G. N., Maharjan, P., Maphosa, L., Vakani, J., Thoday-Kennedy, E., and Kant, S. (2019). A robust automated image-based phenotyping method for rapid vegetative screening of wheat germplasm for nitrogen use efficiency. Front. Plant Sci. 10, 1372. doi: 10.3389/fpls.2019.01372

O'Brien, T. A. (1960). The influence of nitrogen on seedling and early growth of perennial ryegrass and cocksfoot. N Z J. Agric. Res. 3, 399-411. doi: 10.1080/ 00288233.1960.10418095

Poiré, R., Chochois, V., Sirault, X. R. R., Vogel, J. P., Watt, M., and Furbank, R. T. (2014). Digital imaging approaches for phenotyping whole plant nitrogen and phosphorus response in brachypodium distachyon. J. Integr. Plant Biol. 56, 781-796. doi: 10.1111/jipb.12198

R Core Team (2017). R: A language and environment for statistical computing. Vienna, Austria. VSN International, 2015. Genstat for Windows 18th Edition. (Hemel Hempstead, UK: VSN International).

Raun, W. R., and Johnson, G. V. (1999). Improving nitrogen use efficiency for cereal production. Agron. J. 91, 357-363. doi: 10.2134/agronj1999.00021962009100030001x

Rawnsley, R. P., Smith, A. P., Christie, K. M., Harrison, M. T., and Eckard, R. J. (2019). Current and future direction of nitrogen fertiliser use in australian grazing systems. Crop Pasture Sci. 70, 1034-1043. doi: 10.1071/CP18566

VSN International (2015). Genstat for windows 18th edition VSN International.

Wilkins, P. W., Macduff, J. H., Raistrick, N., and Collison, M. (1997). Varietal differences in perennial ryegrass for nitrogen use efficiency in leaf growth following defoliation: Performance in flowing solution culture and its relationship to yield under simulated grazing in the field. Euphytica 98, 109. doi: 10.1023/A:1003080007976

Wilkins, A., Mytton, and Wilkins, (2000). Differences in the nitrogen use efficiency of perennial ryegrass varieties under simulated rotational grazing and their effects on nitrogen recovery and herbage nitrogen content. Grass Forage Sci. 55, 69-76. doi: 10.1046/j.1365-2494.2000.00199.x

Conflict of Interest: The authors declare that the research was conducted in the absence of any commercial or financial relationships that could be construed as a potential conflict of interest.

Copyright (C) 2020 Wang, Dimech, Spangenberg, Smith and Badenhorst. This is an openaccess article distributed under the terms of the Creative Commons Attribution License (CC BY). The use, distribution or reproduction in other forums is permitted, provided the original author(s) and the copyright owner(s) are credited and that the original publication in this journal is cited, in accordance with accepted academic practice. No use, distribution or reproduction is permitted which does not comply with these terms. 